\title{
GCU
}

Glasgow Caledonian

University

University for the Common Good

\section{Building on Wenger: communities of practice in nursing}

Andrew, Nicky; Tolson, Debbie; Ferguson, Dorothy

Published in:

Nurse Education Today

Publication date:

2008

Document Version

Author accepted manuscript

Link to publication in ResearchOnline

Citation for published version (Harvard):

Andrew, N, Tolson, D \& Ferguson, D 2008, 'Building on Wenger: communities of practice in nursing', Nurse Education Today, vol. 28, no. 2, pp. 246-252. <http://www.nurseeducationtoday.com/article/S0260-

$6917 \% 2807 \% 2900072-X / a b s t r a c t>$

\section{General rights}

Copyright and moral rights for the publications made accessible in the public portal are retained by the authors and/or other copyright owners and it is a condition of accessing publications that users recognise and abide by the legal requirements associated with these rights.

Take down policy

If you believe that this document breaches copyright please view our takedown policy at https://edshare.gcu.ac.uk/id/eprint/5179 for details of how to contact us. 


\section{Title}

BUILDING ON WENGER: COMMUNITIES OF PRACTICE IN NURSING Word Count - 4,500

\section{Authors}

Nicola Andrew MN, RNT, RMN (corresponding author)

Lecturer, School of Nursing, Midwifery and Community Health, Glasgow Caledonian University, Cowcaddens Road, Glasgow, UK.

Telephone-44-141-331-8320

Email-n.andrew@gcal.ac.uk

Fax-0131-331-8312

Debbie Tolson PhD, MSc, BSc, RGN

Professor of Gerontological Nursing,

School of Nursing, Midwifery and Community Health, Glasgow Caledonian University, Cowcaddens Road, Glasgow, UK.

Telephone-44-141-331-3463

Email-d.tolson@gcal.ac.uk

Fax-0131-331-8312

Dorothy Ferguson EdD, MPH, BA (Hons), RGN, SCM, RHV, OHNC, HVT Head of Division (Community Health)

School of Nursing, Midwifery and Community Health, Glasgow Caledonian University, Cowcaddens Road, Glasgow, UK.

Telephone-44-141-331-3469

Email-d.h.ferguson@gcal.ac.uk

Fax-0131-331-8312

\section{Key words}

communities of practice, community engagement, nursing, knowledge generation, practice development, organisational development 


\section{Abstract}

Communities of practice (CoPs) provide a potentially useful practice based framework for constructing work based collaborative learning and promoting engagement with local and professional groups and communities. In nursing, we have, increasingly, to manage and deploy new and existing knowledge, although CoPs are currently not widely used to do this. This paper debates the framework created by Wenger and reviews the role of the CoP as an innovative way for educators and practitioners to collaborate to develop and manage new knowledge and emerging practice.

\section{Introduction}

A community of practice (CoP) is a model of situational learning, based on collaboration among peers, where individuals work to a common purpose, defined by knowledge rather than task (Wenger 1998). There are two main perspectives on situational learning. The first is an activity based constructivist view, emphasising the importance of context specific learning in schools and in work practice (Resnick 1987, Barab and Duffy 1999). The second is an anthropological one, in which learning arises from participation in a wider social network (Lave and Wenger 1991). In Higher Education (HE) the inclusion of civic and economic interaction with a wide range of communities, including local, professional and business stakeholders is an increasing trend. This represents a change in HE, which has traditionally been associated with the attainment of individual and not collective goals (Houldsworth and Mathews 2000). 
As a tool for knowledge management and integrating scholarship, a CoP can provide a platform for collaborative work place learning, leading to practice development and the creation, management and dissemination of new knowledge. The original concept does not specifically relate to nursing, indeed CoPs are not widely used in nursing, however they can be found in a diverse range of professions and occupations (Wenger et al 2002).

This article focuses on the concept of communities, with reference to the CoP framework created by Lave and Wenger (1991) and debates its potential application in nursing as a gateway to enhanced professional and educational networking.

\section{Community engagement}

Bond and Paterson (2005), Scottish academics, suggest that the issue of community engagement in the HE sector is becoming increasingly important. The impact of mass higher education has led to an expansion of the HE sector to accommodate an increasingly diverse population, bringing universities out of the shadow of elitism and into the arena of public accountability. Increasingly HEl'S are striving to work in, and engage with, a variety of communities. Such collaborations can range from general consultation to active participation, described by Buys and Bursnall (2007) as 'the coming together of diverse interests and people to achieve a common purpose' (P73). They maintain that academics have not generally engaged in partnership with non academic communities, traditionally viewing them as research objects rather than research partners. 
Collaboration between practitioners and academics has historically been regarded as difficult. Academics may lack respect for practitioner or local knowledge, believing that the resulting research may lack rigour. Conversely practitioners or local partners may feel that academics have little of a practical or applied nature to offer. This is highlighted in nursing where the integration of research and practice remains a controversial and unresolved issue (Buys and Bursnall 2007, Booth et al in press).

\section{The value of communities}

Winter et al (2006), Australian academics, argue that Universities want to be perceived as active community partners and acknowledged 'sites of citizenship', contributing to the local social and economic infrastructure. They argue that community engagement 'must be core business to the university rather than an extraneous activity' and maintain that leadership is required to enable institutional 'recognition and reward of community engagement in teaching and learning' (p221).

In a revival of the Town and Gown debate, Bond and Paterson (2005) critique the position of the university within the local community from the perspective of individual academics. They argue that universities in the UK, including the 'ancients', have a tradition of vocation and sense of community purpose, which is exemplified by their role in the preparation of professionals in areas such as medicine and more recently nursing. Bond and Paterson (2005) note that in $\mathrm{HE}$, while there seems to be a general agreement that increasing community engagement is desirable and valuable, there is little empirical 
evidence to demonstrate the results of such partnerships. Winter et al (2006) believe that the value of communities in HE may not be easily quantified in financial terms. They argue that their true worth is more likely to be in relation to their role in the production and dissemination of knowledge and the development of professional values, which may eventually prove to be valuable in terms of research or project grants. Initially however the advantages may not immediately translate directly into institutional goals and targets.

Unlike local or recreational communities, a professional community is one that forms within the work place as a way of sharing practice and promoting professional collaboration. Etienne Wenger, an American academic and business consultant, is a prolific writer on the value of communities as a tool for work place learning and knowledge management. Wenger et al (2002) believe that knowledge management should be accorded the same importance as any other business asset. They argue that it should not be managed by chance but should be organised in such a way, that its creation and deployment continuously drives the organisation forward. Knowledge, if it is to be of value, has to keep the organisation at the 'cutting edge' of innovation and should be managed 'as companies manage other critical assets' (p6). 


\section{Wenger's Communities}

The themes of belonging, participation, and collaboration are central to the development; function and sustainability of a CoP. Wenger et al (2002) describe CoPs as:

'Groups of people who share a concern, a set of problems, or a passion about a topic, and who deepen their knowledge and expertise in the area by interacting on an ongoing basis'

They discovered that like minded people in areas as diverse as insurance, oil and engineering companies, formed communities within the workplace, however they also observed that wherever these communities occurred, they shared three common domains:

Knowledge: creates common ground and common knowledge within the community. Community: creates the social fabric of learning.

Practice: a set of frameworks, ideas, tools, information, styles, language, stories and documents shared by the community.

(Wenger et al 2002)

Mitchell (2003), an Australian educational consultant, transferred Wenger's original, industry based domains into the Australian state education system. He identified 'practice' as the weakest and least defined domain. Mitchell (2003) believes that community members must locate the investigation of their practice, including development of knowledge products such as documents 
and tools, at the 'heart of the community' (P 39). Allee (2000), an American writer on knowledge networks, observes that; 'knowledge cannot be separated from the communities that create it, use it and transform it' (p4).

Wenger (1998) observes that CoPs evolve from the things that individual's value or that they rate as important. Even when subject to organisational strictures and boundaries, it is the community and not the organisation that generates the knowledge. The life cycle of a community is dependant on its continuing value to its members. CoPs utilise a gatekeeper of knowledge approach to provide an effective mechanism to enable organisations to 'build, share and apply deep levels of competence' (Wenger 1998:4). Snyder (1997), an American academic who worked closely with Wenger, suggests that in this context, competence implies not just a level of academic attainment but an ongoing developmental process as well as a behavioural approach.

A CoP differs from a network because it is 'about something' and not just a set of informal relationships. It continues to exist because it produces a 'shared practice as members engage in the collective process of learning' (Wenger 1998: p4). Lave and Wenger (1991), Wenger (1998) and Wenger et al 2002) promote CoPs as a gateway to informal professional learning, suggesting that, when embedded in the workplace, they can create identity and give meaning to professional practice. Wenger (1998) and Wenger et al (2002) suggest that they can map a path to the understanding of complex professional issues and provide micro-level responses to work related 
problems; they both complement and substitute for formal learning mechanisms.

The original work undertaken by Lave and Wenger (1991) brought CoPs to the attention of the American business and academic communities. Subsequent research by Wenger (1998) and Wenger et al (2002) has influenced educational development in America and in the UK, however the authors and the concept are at times criticised within the literature. Boud and Middleton (2003) assert that CoPs may not be 'useful or sufficient' frameworks to underpin learning at work and problem analysis (p195). They also dispute claims that they can provide a framework for the collection and dissemination of informal learning.

Knowledge generated from informal learning is often not acknowledged, valued or exploited within organisations. In many cases, it is seen as a mechanism for 'doing the job properly and is thus rendered invisible as learning'. Consequently, its value is lost and not deployed or disseminated throughout the organisation (Boud and Middleton 2003 p195). Visibility and sustainability in the longer term, depends on the development and dissemination of practice, to enable fledgling communities to become established, valued and ultimately, sustainable (Mitchell 2003).

\section{Communities of practice or professional communities?}

Kupferberg (2004), in a rigorous critique of the Lave-Wenger paradigm, contests Wenger's belief that CoPs exist everywhere and at every level. $\mathrm{He}$ 
argues that Lave and Wenger (1991) and Wenger (1998) have systematically 'misread the modern landscape of learning' through their narrow interpretation of the underpinning theory (p4). Kupferberg (2004) believes that professional identity starts to form long before an individual enters their chosen profession. He argues that Wenger's view is too narrow and overlooks the fact that talented individuals are often identified and nurtured professionally from an early stage in their development. Kupferbergs' definition of professional communities differs from Wenger's description of CoPs. He focuses on the commitment and contribution individuals make to a subject or discipline long before they enter the professional arena. Wenger's CoPs however reflect the motivation of those entering vocational disciplines, such as nursing, who have limited opportunities to develop true professional identity before they leave school.

The difference lies in the nature of the community. A CoP is a useful tool for collaboration and knowledge management within a mainly professional or vocational context. These communities are usually time limited and thrive or die depending on member engagement. A professional community (such as art or music) promotes career long identification with a discipline group that does not require constant active engagement to survive.

Although Wenger et al (2002) believe that CoPs can evolve anywhere that individual's are drawn together by shared interests, their focus of interest is those that contribute to overall organisational development. Wenger (1998) argues that workplace CoPs evolve because individuals wish to develop a 
professional identity and fit in with their peers. He firmly believes that the desire to learn and belong arises from individual motivation and continues to develop as the result of ongoing work centred engagement and collaboration. The belief that learning arises from motivated, work based social participation, is central to Wenger's work. Kupferberg (2004), on the other hand argues that this belief is unsubstantiated and lacking in sophistication. Wenger (1988) assumes that individuals within a career or work discipline are motivated by an inherent and self-generated desire to learn. Kupferberg (2004) argues that Lave and Wenger (1991) consistently fail to evidence or support their original theory underpinning CoPs. He maintains that the motivation to learn in professional and vocational occupations is more complex than described by Wenger (1998) and Lave and Wenger (1991). He illustrates this point by describing the motivation levels of a group of qualified nurses, the findings of an earlier study, concluding that motivation depends on extrinsic as well as intrinsic factors (Kupferberg 1999).

Kupferbergs' nurses emerge into a profession that exhibits all the characteristics of 'cultural lag'. Their expectations of professionalism and status do not match the reality. As a result, they become vocationally paralysed and consequently fail to move on. Psychologically, they remain 'on the same level as when they decided to enter the profession' (Kupferberg 2004 p5). He suggests that their reluctance to move forward is related to a lack of extrinsic motivation, whereas Wenger's beliefs are based on the idea that individuals are motivated by an intrinsic need to develop shared professional values and identity. The self-determination of individuals is 
central to Wenger's theory and is also reflected in the way in which he views aspects of community engagement.

\section{Member engagement}

Wenger (1998) describes the community development process as fluid, with members leaving and joining, being more or less active at different times. Participant passivity is re-visited in Wenger et al (2002) where the authors review stages of active and passive engagement, revealing a paradox. At certain times, members actively choose to be passive in order to observe the interactions of other members. They conclude that active passivity is reflective of real life situations, where community members, like individuals generally, are more likely to be active at points of direct personal relevance. They then retreat into passive or observation mode when community concerns are not directly relevant to them. An apparently inactive member however may use their passive observations elsewhere, to inform other parts of their life and work (Wenger et al 2002).

Hildebrand (1999) observes that Lave and Wenger's (1991) CoPs permit and tolerate a high degree of participant passivity. She maintains that this passivity reflects Wenger's (1998) attitude to new community members. Wenger (1998) indicates that the intellectual rhythm of the community of practice remains relatively undisturbed by the introduction of new members. Hildebrand (1999) however believes that the ripples are minimal because the new member 'is simply inculcated into the current power/knowledge regime of the community' (p6). Wenger (1998) strongly believes that membership of a 
CoP automatically engages the individual in active participation within both professional and social dimensions. He maintains that it is this act of engagement that forms networks and provides the building blocks of professional identity.

\section{Communities of practice in nursing}

Andrew and Wilkie (2007), in an editorial debating the nature of scholarship in nursing, observe that it is not well defined and continues to be regarded by practising nurses mostly as an academic occupation. They suggest that this perception exists because 'practitioners and academics operate largely within separate communities' (p1). Bond and Paterson (2005) highlight the fact that academics are more likely to regard communities as potential research participants than research partners. Boyer (1999), an influential American academic, believed that this view promoted elitism and discouraged practitioner participation. Wenger's (1998) work promotes an ethos of learning and practice based knowledge development through active engagement in practice within a CoP.

The fact that individuals are motivated to join a CoP primarily to develop a sense of identity and belonging is central to Wenger's (1998) belief. Learning arises out of the act of social participation and evolves through community engagement and collaboration over time. Van de Ven and Johnstone (2005) discuss the nature and function of communities in education. They conclude that scholarship, if it is to be of lasting value, must harness the strengths of both academics and practitioners. In nursing, the complexity surrounding the 
relative positions of theory and practice means that collaborative working is not yet fully embedded into the profession. As a way forward, scholars and clinicians could use this approach to underpin collaborative professional networking and to achieve greater theory/practice alignment (Peseut 2004, Andrew and Wilkie 2007).

Young and Mitchell (2003) promote CoPs as a tool for transferring knowledge and developing skills. They believe that 'communities of practice have the potential to be an organisation's most versatile and dynamic knowledge resource' (p3). As an interface between education and industry or practice, such communities may have the potential to reshape professional practice and improve productivity.

Experienced nurses can potentially exploit a CoP-based approach to challenge and change outdated care practices and manage the resulting knowledge. Through the formation and establishment of 'dynamic and engaged relationships' a CoP has the potential to bridge 'established and emerging practices' (Macdonald 2002 p174).

\section{Challenging practice}

Macdonald (2002), debates the concept of transformative unlearning and suggests that nurses will, if properly prepared, 'unlearn a trusted nursing practice' when presented with new evidence in the form of research or guidelines ( $p 171)$. She discovered few references to unlearning but reviews a range of literature to support a 'spiral path', described as her own journey 
through unlearning (p170). She describes unlearning as the letting go of out dated practices of the past, to allow for the understanding and deployment of new knowledge. By entering into a period of critical reflection, the practitioner is effectively engaging in a process of unlearning, making room for new, evidence based, practices. This period of reflection acts, as a bridge between past and present.

Argyris (1991) discusses the ways in which practitioners can challenge, change and develop practice through the medium of single and double loop learning. Single loop learning, by definition, often conveys the inability of professionals to examine their own behaviour when confronted by challenges to cherished views and opinions. Professionals nurture and protect a body of knowledge. When that knowledge is challenged, the resulting defensive and protective attitude may in the long term inhibit rather than promote learning. Double loop learning on the other hand, encourages challenge and urges practitioners to participate in the design and action of change through open exploration, collaboration and evaluation (Argylis 1991).

A CoP is a democratic way of working, encouraging shared leadership and working, therefore increasing the likelihood of double loop learning occurring. Educators, practitioners and researchers in nursing can potentially collaborate within this framework to underpin change in practice and disseminate the knowledge at local and national levels (Macdonald 2002). 


\section{Practice development}

Kitson (2006), a respected nursing academic, believes that a lack of willingness to engage, invest in and nurture nursing academic/practice partnerships has contributed, in part, to the perception of nursing as a discipline whose infrastructure is still emerging. Reflecting on the professional standing of nursing, she observes that theory/practice integration remains the principle challenge. Individual nurses continue primarily to identify with either education or practice but rarely with both. This partisan attitude may arise, in part, because nurses still do not feel that they either have, or are given, the skills that are necessary to integrate theory and practice (Roxburgh 2006).

Rolfe (2005) in a robust, opinion led article argues that the way in which the majority of nurses may want to assess, enhance and subsequently change practice has been downgraded. He suggests that an outdated obsession with medical research has resulted in an erosion of the value of quantitative approaches. The resulting devaluation of small but (according to Rolfe), valuable studies, containing a richness of data not usually achieved in quantitative studies, has in part, contributed to practitioner apathy and antipathy (Rolfe 2005).

A CoP recognises the symbiotic relationship of theory and practice. Wood (2006), in an editorial on the topic of the inter-relatedness of nursing and research, observes that the research process is much more than simply drills and protocols. If the learning environment evolves within practice, opportunities for professional/practice development are greatly increased. 
She maintains that practitioners need to see research and nursing together in action within a practice-based environment.

From 2000-2003, 30 practising nurses, Scotland, wide, operated as a CoP within the framework of the Gerontological Nursing Demonstration Project (GNDP). They collaborated online and in real time, with university academics, to form a nursing CoP, designed to challenge outdated practice and promote professional and practice development in Gerontological Nursing (Tolson et al 2005). The community was rooted in practice, interacted online, on a weekly basis and authored and tested several Best Practice Statements, now widely distributed throughout Scotland (wwwgeronurse.com). This initiative blended the dual approaches of practitioners and academics to create a successful, thriving and productive CoP. Members worked together in an environment where their different approaches to practice development were valued and encouraged and not automatically pegged as a disadvantage (Booth et al in press). The CoP challenged the traditional view of research and achieved scholarship through 'negotiation and collaboration between researcher and practitioner, (Van de Ven and Johnstone 2005, p.20).

Boyer (1990) in his influential work, Scholarship Reconsidered, encouraged academics to challenge the traditional boundaries of research, urging them to include a practitioner led element to provide findings that were directly relevant to practitioners. CoPs may not bring instant economic benefit to the host institution, their value lies in the areas of knowledge rather then economic development (Winters et al 2006). In nursing, Booth et al (in press) 
have contributed substantially to scholarship and community engagement by promoting a way forward that not only involves academics and practitioners in practice change and development but expanded to include the voices of both service users and carers.

\section{Conclusion}

The nature of working in $\mathrm{HE}$ is changing, moving from the promotion of predominately individual goals, to an increased emphasis on engagement with both local and professional communities. The value of such partnerships, in economic terms is unclear. In the longer term, it may be viewed in terms of research related monies that result from community endeavour; however it is the less tangible contribution to knowledge development and professional learning that may prove to be their greatest asset.

As a vehicle for the creation and management of knowledge systems, CoPs have the potential to release the creativity of practitioners and allow the sponsoring organisation to harvest and disseminate the knowledge they produce. The literature reveals some criticism of the Wenger's approach to community development, suggesting that a CoP is, in reality, a simplistic and unrealistic answer to a complex issue. Central to this is the concept of the development of professional identity. A CoP is primarily concerned with the development of professional identity once the individual is within a profession. In a traditional academic learning community, such as art and music, talented individuals tend to emerge and are nurtured at an earlier stage in their development. 
In nursing, CoPs have the potential to allow practitioners and academics to collaborate to challenge and change practice. As an approach to community engagement, this way of working has the potential create a vibrant work and learning environment. The fluidity of the framework encourages practitioners and academics, to integrate incrementally, the dimensions of research, education, clinical practice and user experience, to respond to the increasing demand for wider institutional and professional awareness.

The CoP framework offers a knowledge development and management system designed to facilitate the integration of scholarship and professional practice. The quality, complexity and transferability of real life, as experienced by service users and providers, can be harnessed and given voice, through collaboration with university based academics and researchers. 


\section{References}

Allee, V. 2000. Knowledge Communities and networks of practice.

OD Practitioner Online

Available from:

http://www.odnetwork.org/odponline/vol32n4/knowledgenets.html

Andrew, N., Wilkie, G., 2007. Integrated scholarship in nursing: an individual responsibility or collective undertaking. Nurse Education Today 27 1-4.

Argyris, C., 1991. Teaching smart people how to learn.

Harvard Business Review 69 (3) 99-109.

Barab, S. A., Duffy, T., 1999. From practice fields to communities of practice, in Jonassen, D., Land, S., (eds) Theoretical foundations of learning environments, Lawerence Erlbaum, Inc.

Bond, R., Paterson P., 2005. Coming down from the ivory tower? Academics' civic and economic engagement with the community. Oxford Review of Education, 31 (3) 331-351.

Booth, J., Tolson, D., Hotchkiss, R., Schofield, I. Using action research to construct national evidence based nursing care guidance for gerontological nursing (in press).

Boud, D., Middleton, H., 2003. Learning from others at work: communities of practice and informal learning. Journal of Workplace learning 15 (5) 194-202. Boyer, E.L., 1990. Scholarship reconsidered: Priorities of the Professoriate. Carnegie Endowment for the Advancement of Teaching, Princeton, New Jersey. 
Buys, N., Bursnall, S., 2007. Establishing university -community partnerships: processes and benefits. JJouranl of Higher Education Policy and Management 29 (1) 73-86.

Ford, P., McCormack, B., 2000. Future directions for gerontology: a nursing perspective. Nurse Education Today 20 389-394.

Fowler, C. J. H., Mayes, J.T., 1999 Learning relationships: from theory to design. Association for Learning Technology Journal, 7(3) 6-16. Published in (Squires, D., Conole, G., Jacobs, J. Eds) The changing Face of Learning Technology. University of Wales Press, Cardiff (2000).

Greeno, J. G., 1998. The situativity of knowing, learning and research. American Psychologist, 53 (1) 5-26.

Hildebrand, G. M., 1999 Contesting learning models.

Paper presented at the AARE and NZARE conference, Melbourne December 1999.

Available from: http://www.aare.edu.au/99pap/hil99582.htm

Houldsworth, C. , Mathews, P., 2000. Group performance, composition, performance and educational attainment. Education and Training, 42 (1) 4053.

Kelly, T., Tolson, D., Schofield, I.,Booth, J., 2005. Describing gerontological nursing: an academic exercise or prerequisite for progress. International Journal of Older People Nursing in association with Journal of Clinical Nursing, 14 (3a) 13-23.

Kitson, A., 2006. From scholarship to action and innovation. Journal of Advanced Nursing, 55(5) 543-545. 
Kupferberg, F., 2004. Professional communities and the life history method. Paper presented at the ESREA- Conference in Rosklde. 4-7 $7^{\text {th }}$ March 2004. Available from:

http://www.esrea.org/conferences/Esrea\%202004/ESREA-papers/kupferb.pdf Kupferberg, F., 1999. Kald eller profession. At intdtraede sygeplejerskerollen. Copenhagen, Nyt Nordsk Forlag.

Lave, J., Wenger, E. 1991. Situated learning, legitimate peripheral participation. University of Cambridge Press, Cambridge.

Macdonald, G., 2002. Transformative unlearning: safety, discernment and communities of learning. Nursing Inquiry 9 (3) 170-178.

Mitchell, J, G., 2003. Effectively structuring communities of practice in VET, ANTA, Melbourne.

Available from: http//www.anta.gov.au

Peseut, D., 2004. The work of belonging [Guest Editorial], Journal of Nursing Scholarship 36 (1) 2 .

Resnick, L. B., 1987. Learning in school and out. Educational Researcher 16 13-20.

Rolfe, G., 2005. The deconstructing angel: nursing reflection and evidence based practice. Nursing Inquiry 12 (2) 78-86.

Roxburgh, M., 2006. An exploration of factors which constrain nurses from research. Journal of Clinical Nursing, 15 535-545.

Schofield, I., 2007. The Gerontological Nursing Demonstration Project. In Shaw, T. \& Sanders, K. (Eds) Foundation of Nursing Studies Dissemination Series 4 (2). 
Scottish Executive Department of Health (SEHD)., 2001. Caring for Scotland: The Strategy for Nursing, Midwifery and Health Visiting. Scottish Executive Health Department, The Stationery Office, Edinburgh.

Snyder, W., 1997. Communities of practice: combining organisational learning and strategy insights to create a bridge to the $21^{\text {st }}$ century. Community Intelligence labs, Available from: http//www.co-i-l.com/coil/knowledge-garden/cop/cols/shtml Tolson, D., McAloon, M., Hotchkiss, R., Schofield, I., 2005 Progressing evidence-based practice: an effective nursing model? Journal of Advanced Nursing, 50 (2) 124-133.

Van de Ven, A. H., Johnstone, P.E.P., 2005. Knowledge for theory and practice.

Available from:

http://webpages.csom.umm.edu/smo/avandeven/Vandeven\&Johnstone\%20K now\%201-25-05pdf.

Wenger, E., 1998. Communities of practice: learning meaning and identity. $\left(6^{\text {th }}\right.$ ed) Cambridge University Press, Cambridge.

Wenger, E., McDermott, R., Snyder, W., 2002. A guide to managing knowledge. Cultivating communities of practice.

Harvard Business School Press, Boston, Massachusetts.

Winter, R., Griffiths, M. \& Green, K., 2000. The academic qualities of practice: what are the criteria for a practice-based PhD. Studies in Higher Education, 25 (1) 25-37.

Wood, M.J., 2006. Nursing practice research and evidence based practice. Clinical Nursing Research, 15 (2) 83-85. 
Young, S., Mitchell, J. 2003. Putting more practice into communities of practice. Paper presented at Australian Vocational Education and Training Research Association (AVETRA) Conference, Australian Technology Park, Sydney, $10^{\text {th }}$ April 2003. 